\title{
Spiritual Care as a response to an exaptation: how evolutionary
}

\section{psychology informs the debate.}

Dr Peter Kevern BSc, BD, PhD

Associate Professor in Values in Care

Faculty of Health Sciences,

Staffordshire University

College Road

Stoke-on-Trent

ST4 2DE

Tel: 01785353762

Email: p.kevern@staffs.ac.uk

Abstract

This paper has its origins in a 2013 proposal by the author, that the concept of 'spiritual care' in clinical settings might fruitfully be grounded in the findings of the Cognitive Science of Religion (CSR). In a recent paper, John Paley rejects the central arguments and asserts his conviction that a model for 'spiritual care' cannot be derived from the insights of evolutionary psychology. In the present paper the author employs a modified form of Fichtean dialectic to examine the contrasting positions and, via a process of analysis and synthesis, identify the key areas for further exploration and research. He concludes, first, that CSR in itself does not provide a sufficient theoretical justification for the notion and practice of 'spiritual care'; secondly, that any attempt to develop a general theory of spiritual care would need to pay closer attention to the role of historically-situated religious communities; and finally, that these objections nevertheless do not amount to an argument against the attempt to provide spiritual care as part of person-centred care. Instead, a 
revised model is proposed which has the potential to provide testable predictions in this field.

Key words: Spiritual Care; Spirituality; Religion; Evolutionary Psychology; Cognitive Science of Religion

\section{Introduction}

'Spiritual Care' has been part of the agenda for nursing and allied health professions for some 40 years, and proponents of the concept argue for its importance as an element in holistic, person-centred care. But it is dependent (in a secular health system in a religiously diverse society) on a conception of human 'spirituality' which in principle can be detached from the historic associations of the term with concrete, collective, organized religions and identified as a universal (or at least widespread) human characteristic.

However, attempts to identify and theoretically explicate such a concept of spirituality have proved problematic. Even proponents of the concept of spiritual care have complained of a concept of spirituality that is a 'marshmallow ... thin, uncritical, dull and un-nutritious' (Pattison 2001) ; and some prominent advocates of the role of religion in healthcare have dismissed the notion as vacuous, arguing that 'spirituality' is either a form of religion, or an incoherent agglomeration of unrelated beliefs and practices (Koenig et al. 
2012; Zinnbauer et al. 1997). Even some proponents of the ideals of spiritual care would argue that it is, at bottom, just good nursing care (Clarke 2013).

Perhaps for this reason, the idea and practice of spiritual care has gained only uneven acceptance. It is well established in Palliative Care (which has religious roots) (Department of Health 2010) but has less purchase in Primary and Acute Care (Mowat et al. 2012; Kevern \& Hill 2015; Cockell \& McSherry 2012). There is also a significant dissonance between the official position of healthcare providers and professional bodies, which remain broadly favourable to the idea of spiritual care, and its teaching and delivery (Lewinson et al. 2015; McSherry \& Ross 2015; Balboni et al. 2014; Rushton 2014; Nascimento et al. 2016).

As I will argue below, this gap between widespread approval for the notion of spiritual care and its delivery in practice is indicative of a certain theoretical and conceptual impoverishment. The current paper represents part of an ongoing project to explore whether a more unified and theoretically-informed model of secular spiritual care may be generated by reference to theoretical and empirical findings in evolutionary studies in the fields of cognitive psychology, sociology and social anthropology. If so, it may provide a basis for testable predictions and experimentation concerning what makes 'good' spiritual care, and how it may be deployed to improve the patient experience and patient outcomes 


\section{Background}

Care for the spiritual needs of patients is now enshrined as a key value in a range of policy documents (see e.g. Cockell \& McSherry 2012; World Health Organization 1998). This progress is remarkable, given that there is no single definition of 'spirituality' which has gained widespread acceptance, or any coherent body of theory underpinning the concept. Instead, there has been a plethora of ad hoc definitions for the purposes of study or benchmarking (e.g. Puchalski et al. 2014) a number of analyses of what the term means to patients or professionals (e.g. McSherry \& Jamieson 2011), and a number of systematic reviews of the way the concept is developed in the existing literature. (e.g. Reinert \& Koenig 2013) Thus, for example, Weathers et al. (2015) undertake a concept analysis of spirituality in the literature and identify three themes: connectedness, transcendence, meaning in life. In effect, they are substituting one indefinable term with three (see also e.g. Gall et al. 2011; Tanyi 2002). The result is, at best, a 'semantic field' (Grandy 1992) on which there is a broad convergence, with little theoretical background or clear boundaries.

This uneasy state of affairs was attacked in a paper by John Paley (Paley 2008a) in this journal, with a challenge which represents a sort of 'emperor's new clothes' moment for proponents of spiritual care. In it, he argued that the notion of patient spirituality lacked any clear content or definition; and 
that its apparent significance for patient care rested on assumptions and commitments borrowed from theology and religious practice which had no place in a secular healthcare system. In a memorable phrase, he claimed that "lack of scholarship has turned the topic into a metaphysical backwater" (p.1)

Paley's paper provoked a flurry of immediate responses and discussion (see e.g. Nolan 2009;Pesut 2008; Paley 2010) which falls outside the scope of this paper and is now of mostly historical interest. In the longer term, there are two main critically constructive lines of thought that have emerged from Paley's paper. The first largely accepts Paley's analysis of the vagueness of 'spirituality', but rejects his conclusion that this thereby renders the term redundant. Instead, so the argument goes, health care needs 'thin, vague and useful' concepts in order to prevent reductionist tendencies towards a single narrow understanding of health and illness (Swinton \& Pattison 2010); to maintain a place for language to do with meaning and purpose (Nolan 2009; Nolan 2011); and to direct professionals' attention to aspects of care that may otherwise be marginalized (Swinton 2011; Swinton 2014). Such concepts, so the argument goes, are integral to the ecology of health care: compare, for example the ideas of Dignity, Compassion, or Diversity.

The second response is the one that I tried to develop in my 2013 paper (Kevern 2013a). In it, I sought to address the obvious theoretical deficiency that had condemned the study of spirituality to a "metaphysical backwater". I argued that the concept may be capable of clearer and more consistent 
theoretical grounding by drawing on key findings from evolutionary psychology and the cognitive science of religion. In these fields, researchers were finding empirical results which helped to cast light on why religious or spiritual beliefs were so widespread and persistent, to do with the way the human brain had evolved to manage threats and support communal living. I argued that these provided a persuasive (if incomplete) explanation for why 'spirituality' was widespread; what features could reasonably be expected to crop up repeatedly; how they might impinge upon the patient experience; and how studies might be constructed to test and evaluate appropriate spiritual care by way of response. (Kevern 2013a).

The overall thesis was that, although an individual's spiritual and religious dispositions were clearly deeply influenced by their culture and context, there was a demonstrably universal element to spiritual intuitions which derived from the evolved structure of human cognition: there were 'spiritual universals' which could be accounted for as outcomes of the human evolutionary story. Consequently, there were, potentially, universal features of spiritual care which could be applied irrespective of the particular religious, or nonreligious, attitudes of the patient.

John Paley recently did me the honour of constructing a critical response in the pages of this journal (Paley 2015), for which I am triply grateful. In the first place, it reassured me that there is a case to answer here, and so a question worthy of further exploration. In the second, his critique helped to 
clarify the questions, refine the issues and core concepts, and point to where further work needs to be done in order to evaluate and develop this approach. Finally, therefore, by his response he has moved the exploration on: he has stimulated a wider and deeper conversation about the potential and limitations of attaching the term 'spirituality' to a particular set of intuitions and emotions which arise in the brain as a result of its evolutionary history.

The current paper thus represents the fourth stage in an ongoing discussion which, I hope, will eventually lay the groundwork for a theory of patient spirituality and spiritual care.

\section{Method}

Paley's paper took the form of a refutation (as demonstrated by its title) and it would be straightforward to continue the conversation in an adversarial mode. To do so, however, would be to distort the fact that in many of the key disputes, Paley and I are in effect on the same side: we both reject the current construction of 'spirituality' as inadequately defined and, perhaps, inappropriately 'religious'; we would both like to see health care in which an intervention is judged on its own merits, where scientific theories are generated and deployed to refine existing practice, and where these are then 
evaluated by the examination of an evidence base. The main difference is whether we believe talk of 'spirituality' can be brought into this cycle of practice-theory-evidence-evaluation or is a dubious and unmanageable interloper.

I therefore propose a more collaborative and reflective approach, based upon the Fichtean dialectic of thesis-antithesis-synthesis (Fichte 1982). In other words, I shall seek to bring the two papers into a critical conversation with a view to identifying, beyond the thesis-antithesis dialectic, a new synthesis which exceeds the positions of either paper.

This approach indicates that my response to Paley's critique will require four stages:

1. Thesis and antithesis. Summary of my argument and Paley's response

2. Dialectical analysis. A critical discussion of arguments and counterarguments for our divergent positions with a view to distinguishing those issues on which no agreement is possible; and those in which the antithesis casts light on and extends the thesis

3. Synthesis. Discussion and speculative development of those issues in which further reflection or research can cast light on the central problems

4. Conclusion. Summary of findings to date and restatement of central issues. 


\section{Thesis and antithesis}

For the sake of brevity, the summary of key points from my original proposal and Paley's response will only be sketched in here, and will inevitably therefore overlook some of the finer points on both sides of the argument. The purpose of this section is not to rehearse each move in the respective arguments, but to provide a clear enough sense of their structure and overall direction to enable a more detailed identification and analysis of the key issues in the sections that follow.

Thesis

The paper (Kevern 2013a) does not attempt to be an objective argument for or against the practice of spiritual care in a healthcare setting, but is addressed to readers who believe that "the notion of 'spirituality' points 
(however vaguely) to something fundamental in human beings and therefore in person-centred care" (p.9). I contend that there is little prospect of 'spiritual care' gaining any traction in healthcare contexts unless and until it can be provided with some conceptual clarity and a theoretical basis for engaging in it. Thus, to establish the role of spiritual care in a secular and materialist context, it is necessary to have an account of "why it is important, what its main features are and how it may function in a healthcare context." (p.9)

The emerging 'standard model' deriving from the Cognitive Sciences of Religion offers a possible theoretical framework for this project. It suggests that, as a predisposition to religious beliefs (or, as I would now prefer to call them, 'spiritual intuitions'): 'spirituality' "may have a place in the very architecture of the human brain, long before 'religion' shapes and conditions it." (p.10)

In the paper itself, I stress that this model is inadequate as a general account of human beings' spirituality, religiosity and spiritual needs. In practice, religious and spiritual beliefs are historically acquired, socially mediated and reinforced. There is therefore generally no straightforward transition from a description of typical spiritual intuitions through spiritual needs to a prescription for the satisfaction of them in 'spiritual care'. However, patients in a hospice or hospital context share some particular circumstances which may increase the salience of this model of spiritual intuitions. In general, they 
are separated from their usual sources of religious dogma and are reappraising their religious beliefs in the light of stressful, existentiallychallenging circumstances. This may mean that their 'early-emerging and cognitive biases' (Bloom 2009 p.124) have particular salience and power.

If this is the case, there may well be identifiable, widespread themes which can be expected to recur among patients in acute care regardless of whether such patients are explicitly religious or not. These may provide the basis for an empirical and reductionist account of the importance and focus of spiritual care that may appropriately be applied in a secular context. "Specifically, there are three key areas ....- around the ascription of agency in events, purpose to objects and occurrences, and the way in which 'belief' is achieved and validated - which may repay careful attention in ensuring the best outcomes for patients" (p.15). An early attempt at applying these insights to the evidence base on 'religious coping' forms the substance of a companion paper, which however falls outside the scope of the current debate (Kevern 2012a).

\section{Antithesis}

Paley's response weaves together a number of divergent themes which resist a single clear account. But it revolves mainly around a dichotomy between 
properties 'selected-for' by evolution, and what he terms 'evolutionary accidents':

According to most CSR researchers, religion is a by-product of evolution (Murray \& Goldberg 2005). This means that, although the dedicated cognitive mechanisms referred to above were selected for directly, religious beliefs and practices were not. Rather, they are an incidental consequence of those dedicated mechanisms. In other words, religious belief is an 'evolutionary accident' (Bloom 2009 p.118). There are numerous examples of this kind of evolutionary contingency. A classic example from human anatomy is the 'belly button' (Buss et al. 1998). The navel is not an adaptation; it has no survival function in itself. Rather, it is a by-product of the umbilical cord, which is a genuine adaptation . . .

... Since reference to supernatural agents is a natural extension of the relevant cognitive systems, the acquisition of these systems made human beings susceptible to religious discourse. If religion corresponds to the belly button, these cognitive mechanisms correspond to the umbilical cord. (Paley 2015 p.214)

Paley's central contention is that I have confused evolutionary contingencies with selected-for consequences, and so been led into four logical nonsequiturs and an 'undefended assumption': 
1. The fundamental-in-person-centred-care non-sequitur. My use of the term 'fundamental' will be considered in more detail in the next section and need not be rehearsed here. The main issue for Paley is that he understands me to mean that 'religion' (undefined) is therefore hardwired and inevitable. He concludes, "Kevern's non-sequitur, and his argument more generally, trades on an ambiguity in the idea that religion is, in CSR terms, 'fundamental' or 'natural' . . . he is fudging the distinction between a selected-for characteristic, and a nonselected-for-consequence-of-a-selected-for-characteristic" (p.217).

2. The balanced-mental-state non-sequitur. Even if religion were 'natural', "It does not follow that, according to CSR, religion is necessary, basic, beneficial, healthy, mentally healthy, indispensable, an essence, a good thing, or the core of human existence."

3. The coming-to-religious-belief-alone non-sequitur. This seems to rest for Paley on the assumption that my statement that CSR gives priority to the individual implies ontological or temporal priority: "Kevern seems to think that, if this is true, them (according to CSR) religious beliefs must first be acquired by individuals, and then must afterwards be 'reinforced' by religious insititutions" (p.218).

4. The isolated-individual-switch-on non-sequitur. In Paley's own words, "This misunderstanding [about the priority of the individual] pervades almost all of what Kevern has to say. Most significantly, he is under the impression that CSR mechanisms apply only, or primarily, to individuals 
... Kevern seems to believe that the CSR modules 'switch on' for people who are isolated, and somehow 'switch off, or cede cognitive salience to some other cognitive system, when the individual is restored to the religious collective." (p.219)

5. The spirituality-as-individual assumption. "Kevern appears to assume that spirituality is by definition an individual matter, intrinsically 'internal' whereas religion is collective and 'external'. (p.219)

Paley concludes his paper with an extended section on 'The spirituality agenda' which I intend to set aside as incidental to the current study. It is a re-presentation of an argument which he has made fairly consistently (Paley 2008a; Paley 2008c; Paley 2009; Paley 2008b; Paley 2010) and which does not relate directly to the topic in hand. Instead, it is a counter-narrative of the type that the anthropologist Evans-Pritchard notoriously characterized as a 'Just-so' story (Evans-Pritchard \& Evans-Pritchard 1965): it offers a causal account by linking together some facts and observations, but its persuasiveness lies in its internal coherence and capacity to flesh out existing convictions rather than its testable or verifiable statements.

\section{Dialectical Analysis}

Clearing the ground: points of agreement and clarifications 
Any academic confrontation is liable to create a certain amount of confusion and 'background noise', as the protagonists probe and challenge apparent weak spots in each others' arguments. Given the analytical character of this paper, it is necessary to spend some time defining the contested ground more precisely and so trace out carefully the steps that lead towards the 'Synthesis'. These technicalities will not be of equal relevance or interest to every reader, and those who are not particularly interested in the archaeology of the debate may prefer to skip this section for now and move straight to the substantive discussions in the following one.

At the outset, there are three substantial areas of agreement which are in danger of being masked by the adversarial style of academic debate:

- The basic problem of spirituality in health care. Paley's critique of the use of 'spirituality' in relation to patient care in his earlier papers rests on a number of arguments: the absence of any empirical evidence for the existence of a 'spirit' (Paley 2008a; Paley 2008c; Paley 2009), a distortion due to the jurisdictional claims of the profession itself (Paley 2008b) and the influence of an unacknowledged "strand of Christian theology" (Paley 2008a, p9).

For the purposes of argument, the position of this paper is that Paley is correct in this analysis and in his conclusion that "Methodological agnosticism implies that health professionals should evaluate patients' 
beliefs in utilitarian terms - as they would lifestyle choices - allowing for the possibility, to be studied empirically, that spiritual beliefs sometimes bring health benefits to those who hold them." (Paley 2010, p.183). Where we disagree is only in his assumption that these points mean that talk of spirituality in patient care should be rigorously excluded. On the contrary, they appear to point to the need to evaluate interventions in spiritual care rigorously in terms of their outcomes, rather than by any hypothesized origins in christian theology or the manoeuvrings of ambitious professionals.

- Cognitive models of religion and their elements. The very basic model which I provided in my original paper is considerably expanded in Paley's account, but the essential structure remains the same, along with the claim that there is now a substantial view among cognitive scientists that some of their experimental results cast light on some of the reasons that individuals hold religious beliefs. In sum, we converge around a definition which he quotes from McCauley (2011):

My case has not been that humans are naturally religious, but rather that their maturationally natural cognitive systems develop in ways that make people thoroughly receptive to religions... (p.22) 
Where Paley and I diverge is on the significance and implications of these findings, which will be subject to more detailed analysis later.

- The practical distinction between 'spirituality' and 'religion'. Paley objects to the rough distinction I make (derived from Heelas et al. 2005) between spirituality as 'inner' and religion as 'outer'. For practical purposes, I am content to substitute a distinction which he himself identifies in the literature, between religion as 'institutional' and spirituality as 'universal' (Paley 2008b): the important point is that spirituality (as universal) is presumably individually-held and perhaps innate, whereas religion has a necessarily public and/or organizational aspect.

In addition, there are a few areas in which a confusion has arisen from my use of terms, and Paley's interpretation of them:

1. On spirituality as 'fundamental'. In my earlier paper (Kevern 2013a, p.13) I make the working assumption that "spirituality points to something fundamental in human beings and therefore in personcentred care". Paley points to some difficulties with this statement and, on reflection, it clearly needs more formulation and clarification. I intended to make no universal anthropological claim, but only a 
contingent and practical one: that a full account of person-centred care should include some consideration of those aspects which are typically classified under the term 'spiritual', on the grounds that people do report spiritual or religious distress and it is appropriate to respond to it as such.

2. A 'balanced mental state'. Another stage in my argument at which it suffered from a lack of terminological precision was in the claim that "A practical implication of this finding . . . is that a balanced mental state is more likely to include some transaction with divine beings than not" (Kevern 2013a, p.12). Paley, not unreasonably, interprets this as implying normativity: that a 'balanced' person is one who 'transacts' with divine beings. My intention here was descriptive rather than normative, that person-centred care may therefore entail working with and supporting whatever version of this 'transaction' is (for whatever reason) favoured by the individual concerned.

3. On the 'priority' of the cognitive. In a rather puzzling passage, Paley contends that, "Kevern thinks CSR implies ... that people do come to religious beliefs 'all alone'"' (Paley 2015), an inference that seems to derive form his misunderstanding of the concept of 'priority'. When I stated that CSR gives 'priority' to the individual, this was meant in an epistemological rather than historical sense: in his words, "These cognitive mechanisms are the conditions-of-possibility for religious 
belief as such; local culture fills in the detail of specific creeds and narratives" (p.213), and it is self-evident that specialists in cognitive science will focus their attention on individuals and their cognition (Paley 2015, p.218).

4. Distinguishing spirituality and religion. Given this 'priority', and in the light of the practical distinction made above between 'spirituality' and 'religion', it is clear that when cognitive scientists refer to 'religion', they are talking of the cognitive and therefore individual and potentially universal dimension of religion: in other words, something very similar to what we have just agreed to define as 'spirituality'. Similarly, the literature on religious coping on which I draw in my paper employs the terminology in the specific, narrow realm of individual psychology, and so we are justified in treating that as 'spirituality' within the definition deployed here. Consequently, when Paley objects that "CSR is an account of religion, and CSR theorists rarely talk about spirituality. . . So Kevern needs to persuade us that CSR has something to say about 'spirituality'"' (p.218). he is tripping up on a confusion between two discourses.

As a partial response to this confusion, I will for the purposes of the present paper distinguish between 'spiritual intuitions', as individuallyheld (and possibly unreflective) and the collectively-held, normative status of 'religious beliefs'. Similarly, I will distinguish between 
individual 'spiritual practices' and collective institutionally-sanctioned 'religious practices' . These are, of course, merely heuristic distinctions, and in reality individuals 'individualise' their religious practices as religions 'collectivise' individual ones. The purpose of the distinctions here is simply to bring precision to the discussion at points of potential confusion.

Points of substantive disagreement: the dialectic

Setting aside the points of agreement and clarifications above, there are two broad areas of contention which remain between Paley's position and my own original one. These are the 'framing' account that he gives of religion as a 'spandrel', along with the inference that it is therefore irrelevant to the provision of health care; and the "four non-sequiturs and one unfounded assumption" which he claims undermine my argument.

The 'framing' distinction upon which Paley bases his analysis is between selected-for characteristics (such as agency detection) and what he at one point terms a "a non-selected-for-consequence-of-a-selected-forcharacteristic" (p.218). In this he invokes a common trope in evolutionary arguments, that of the 'spandrel', an image from architecture. A spandrel is an architectural side-product, the necessary infill between two arches that are separated only by columns, which may be decorated and so become an aesthetic feature in its own right but remains a geometrical accident of 
purposeful activity. By analogy, so the argument goes, not everything that evolution throws up is 'meant' to be there: some features are just sideproducts of evolutionary histories which have had another, evolutionarily useful, outcome (e.g. Atran 2004). To illustrate this point, Paley invokes the image of the navel, "a by-product of the umbilical cord, which is a genuine adaptation" (p.218). Similarly, religion is a by-product of our cognitive architecture, which is the genuine adaptation. Not only organized religion, but the spiritual intuitions which represent its internalized counterpart can, he infers, be discounted as both trivial and irrelevant to healthcare.

To summarise the analysis so far, it appears that Paley's critique rests upon two assumptions which appear to be unwarranted: that spiritual intuitions can only be understood as such a "non-selected-for-consequence-of-a-selectedfor-characteristic" as the navel; and that a "non-selected-for-consequence-ofa-selected-for-characteristic" cannot be recognised as a valid need in health care. We will return to these points in the section to follow.

Turning to what Paley claims are my 'four non-sequiturs and an unwarranted assumption", it becomes apparent that three of the 'non-sequiturs' can be set aside without further ado. The fundamental-in-person-centred-care nonsequitur; the balanced-mental-state non-sequitur and the coming-to-religiousbelief-alone non-sequitur rest respectively on a precise interpretation of the terms 'fundamental', 'balanced' and 'priority' which they were never intended to bear. 
However, the final two items, The isolated-individual-switch-on non-sequitur; and the spirituality-as-individual assumption deserve a more careful treatment. Although Paley's charge rests partly on the claims for 'priority' mentioned above, there is a deeper matter at issue here. The burden of my original argument (p.10) was that CSR would have limited value as a way of explicating religious dogma and behaviour in the everyday world, because it deals only with individual spiritual intuitions and cannot be descriptive of socially- and historically- conditioned religious expression. However, it might have potential in the special circumstances of (say) an acute hospital ward in which the social context of religious expression is attenuated and the combined effects of isolation and change-induced stress may predispose towards the sort of minimally-counterintuitive, quick-and-dirty thinking that characterizes spiritual intuitions. What Paley has demonstrated here is the need for a more subtle and comprehensive account of the relationship between religious dogma, religious practice and spiritual intuitions that is less dependent upon the postulation of an extreme 'ideal-type' patient, because there will never be an actual patient who is so isolated (both socially and temporally) from the religious beliefs and practices within which their spiritual intuitions and individual practices are framed.

In the light of this analysis, it appears that there are three issues worthy of further exploration and development. It will not be possible to evaluate the 
claim that CSR could provide 'spiritual care' with a theoretical basis for definition and predictions until the following have been addressed:

1. If the tendency of human beings to have deep-seated spiritual intuitions is to be understood as a 'spandrel', an accidental by-product of the fundamental architecture of human cognition, does it therefore follow that it is not subject to adaptation and change through the operation of natural selection at the level of individuals-in-community?

2. If these spiritual intuitions are to be understood as a 'spandrel', does it therefore follow that they are to be treated as unworthy of attention in the delivery of person-centred health care?

3. If it is not possible to conceive of real patients as 'ideal-type' subjects whose spiritual intuitions and needs derive from their cognitive architecture independently of their socially- and historicallyconditioned religious beliefs and practices, how must the model be developed to take account of possible selective pressures and adaptive behaviour at the level of community?

These considerations will form the basis for the 'Synthesis' section which follows

\section{Synthesis}


It is worth noting that Paley's own argument for his central assumption is surprisingly weak: "according to most CSR researchers, religion is a byproduct of evolution (Murray and Goldberg 2009)" (p.214). An appeal to 'most researchers' is already a weak one, but on analysis is further undermined by two considerations. First, it is not at all surprising that researchers who specialize in the cognitive architecture of individual minds will be particularly appreciative of the evolutionary pressures on those cognitive architectures themselves, at the individual level: it is no criticism of a scientist to say that they will see first what is in their field of view. Secondly, one does not need to widen that field of view very far to find a long tradition of advocates of a contrary opinion to the effect that religion is adaptive, in social anthropology and psychology of religion, but also among cognitive scientists themselves (Baumard \& Chevallier 2015; Johnson 2012; Morewedge \& Clear 2008; Norenzayan et al. 2012; Norenzayan 2013; Norenzayan et al. 2014; Peoples \& Marlowe 2012; Pyysiäinen \& Hauser 2010; Sosis 2009). Indeed, for some reason Paley neglects to add that Murray and Goldberg themselves identify two distinct schools of thought, although they consider the 'adaptationists' to be in the minority among evolutionary theorists of religion at the time they are writing (Murray \& Goldberg 2005 p.183). In the context of this broader and deeper debate on the relationship between evolutionary psychology and religions as socially and historically encountered the simple binary between 'selected-for' traits and useless 'spandrels' quickly proves inadequate on 
several levels, and a more subtle conceptual structure needs to be developed to take account of three additional considerations.

First, the concept of purpose and intention embedded in the notion of a 'selected-for' characteristic needs to be deconstructed, because the concept of purposive activity or intention has been smuggled in to the discourse: a building is built, by builders. To borrow some terminology from Pittendrigh (in Lorenz 1966, p.274), it is acceptable to use purposive language in evolutionary discourse, but only when it is clear such language is being used teleonomically, not teleologically: to speak of the 'purpose' of a feature is to describe what it achieves in the contemporary context, not what it was 'originally for'. In this case, to state that a characteristic such as the Hyperactive Agency detection Device (HADD) (Barrett 2011) was originally 'selected for' because it improved possessors' chances of evading predators does not entail the conclusion that it has no other possible value or costs for the individuals or communities in which it forms part of the phenotype. Applying this line of reasoning to the case under discussion, we may say that the speculative distinction between a "selected-for-characteristic" and a "non-selected-for-consequence-of-a-selected-for-characteristic" has no explanatory value when considering whether spiritual intuitions merit the provision of spiritual care.

Secondly, it does not follow that because a feature was 'originally' for one purpose, it cannot be used for other purposes that have adaptive significance 
(Powell \& Clarke 2012). The fine distinction here is between the terminology of an 'adaptation' (which, it is assumed, developed as a response to specific selection pressures) and a characteristic which is 'adaptive' (in the sense that, even in the absence of the original selection pressures, possession of the characteristic positively of negatively affects the fitness of the individuals or communities). The technical term for the process is 'exaptation' (Gould 1991) or secondary adaptation: for example, feathers are thought to have originally evolved for insulation, but are 'exapted' both for flight, and separately for display (for example, in a peacock's tail). Applying this line of reasoning to the case under discussion, we may say that even if spiritual intuitions are a byproduct of a prior evolutionary process, it does not follow that they have no adaptive value (whether positive or negative) in contemporary social situations; or that therefore they are not worthy of attention as part of person-centred care.

Thirdly, and following directly from the above, it should be clear that there is no warrant for the assumption that section pressures operate in a single direction, at a single level, in order to produce an adaptation. On the contrary, the explanatory power of the concept of natural selection rests largely on its flexibility and applicability at the level of individual proteins, cells, organs, individuals and communities: the basic logical operations can be brought to bear in each case. In relation to the case under discussion, we may plausibly conclude that, as well as spiritual intuitions having adaptive significance, the religious-organisational expressions and vehicles for these 
intuitions in concrete historical and social communities are liable to selection pressures, which themselves may vary over time (Baumard \& Chevallier 2015). In other words, some religious expressions are liable to survive better than others, by a process both of community selection and cultural selection.

It should be noted that, although the operation of selective pressures on religious communities is a logical conclusion (by tautology), it does not follow that the process of selection has any substantive effect upon the structure and expression of actual religious communities in time and space. This remains the most contentious and difficult to demonstrate element of an adaptationist account of religion; and the account being developed here does not depend upon such a conclusion. For more detailed analysis of this option the reader is referred to Sosis (2009); and Powell \& Clarke (2012)

Returning to the three questions which were raised at the end of the previous section:

\section{Spandrels and exaptations}

Applying this line of argument to the present case, it should be clear that it is not necessary to claim that a propensity to spiritual intuitions is 'originally' selected-for in order to claim that such a propensity has adaptive significance 
in the present day in order for it to be subject to selection pressures; and to claim that such pressures are likely to have been operative over a considerable period of time (as evidenced by the emergence of developed, persistent social expressions in organized religions) in order to warrant the assumption it has been shaped by these pressures into different secondary adaptations or 'exaptations' (Sosis 2009).

In sum, the binary between what Paley rather clumsily terms 'a selected-for' and 'a non-selected-for-consequence-of-a-selected-for-characteristic' is an ideologically-driven construction which does not reflect a defensible distinction in evolutionary theory itself. It is quite plausible that the existence of spiritual intuitions is a by-product of a prior selective process; but it does not follow that, therefore, no selection pressure at all has ever been applied to the existence, strength , character or expression of spiritual intuitions, whether at the individual or collective level (as (Powell \& Clarke (2012) say, "This is a considerable evidentiary burden to shoulder"!). However, for the same reasons it is not possible to advance the argument that people in acute care are somehow driven back on their own 'spiritual intuitions' stripped of all context: by definition, these spiritual intuitions have been formed, refined and articulated within particular sociocultural communal religious contexts.

\section{On navels and spiritual care}


The second point at which Paley's argument for the irrelevance of spiritual intuitions seems to fall down is in his inference that, if such intuitions are not directly selected-for, spiritual care can have no role as part of person-centred health care. This seems to be a straightforward non-sequitur. There is ample evidence that a patient's spiritual or religious beliefs and practices can have a significant effect upon their wellbeing and even survival chances (e.g. Zinnbauer et al. 1997; Pargament et al. 2010; Koenig et al. 2012) and it follows that there is a prima facie case for paying attention to these coping strategies as part of overall care. The argument about whether spiritual intuitions are selected-for or "a non-selected-for-consequence-of-a-selectedfor-characteristic" surely has no direct effect on whether we judge 'spiritual care' to be a useful practice in overall person-centred care or not.

To return to the analogy of the navel which Paley introduces, it is obvious that 'originally' this was a by-product of the umbilicus. But it is not impossible to imagine that, for example, poorly-formed navels may be susceptible to infections or hernia; that a particular form of navel be judged by the patient as 'ugly' or shameful; or that peculiar features of the appearance of the navel may have diagnostic significance. The absence of a discernible teleology for the navel does not constitute a prima facie case for excluding it from all medical consideration.

Paley's counter-claim is that I would not treat the human capacity to ascribe agency to moving shapes on a screen (Heider \& Simmel 1944) as similarly 
'fundamental' for person-centred care, but the same logic applies: if a person were reporting, say, anxiety because they were interpreting the movement of one of the shapes as 'bullying' or 'upset', then some intervention would be appropriate. Similarly, if the activity of bassoon playing or playing video games can be shown to assist a patient's recovery, the question of whether it is selected-for or selected-as, or neither, is simply irrelevant.

This reinforces the claim that person-centred care needs to be 'nonfoundationalist', in the sense that it does not attempt to conform to a template of what good health and therefore good care should look like, but adapts to the needs and preferences of each individual for what they consider to be the best outcome in the light of the clinical evidence available. A version of spiritual care that refuses to consider evidence-based interventions to do with religion (or for that matter bassoon-playing) on the grounds that they cannot possibly be referring to a real object in the world would, clearly, be ideologically-driven rather than outcomes-focussed.

\section{On religious organizations and spiritual intuitions}

The argument that I have been developing to this point is that, (even) if the origin and continuing existence of spiritual intuitions is not 'selected-for', the form and expression of these intuitions in real time is almost certainly subject to selection pressures. This means that it is legitimate to understand them as 
having an intimate relationship with our experience of the world and our place in it; that their function and role in relation to patient wellbeing is therefore a subject worthy of study; and that evidence gathered from this study can appropriately be used to guide spiritual care, as part of the general remit of patient-centred care.

However, in this more refined version of my original argument, it becomes apparent that there is a serious shortcoming. If the form and expression of spiritual intuitions is subject to adaptive pressures, these are being applied within the social and historical world of human communities rather than at the level of individual human brains. To put it another way, and using a categorical distinction applied earlier: there is no empirical distinction to be drawn between 'individual' spirituality and 'organisational' religion, since the selective pressures that are brought to bear on the former are mediated through the latter. Thus, any distinction has a purely formal and epistemological status. David Sloan Wilson would take the argument further: once it is allowed that selection is operative on multiple levels from the individual neuron to the community of persons, "If the individual is no longer a privileged unit of selection, it is no longer a privileged unit of cognition. We are free to imagine individuals in a social group connected in a circuitry that gives the group the status of the brain and the individual the status of the neuron." (Wilson 2010 p.33) 
If religion as a whole is to be taken as subject to selection pressures that complement or impact upon cognitively-based spiritual intuitions rather than simply expressing them, then my earlier heuristic move of treating isolated patients in acute hospital care as an ideal-type 'special case' appears unsustainable. The selection pressures on the group, its dogmas and practices cannot be 'bracketed out' of consideration even temporarily in the service of a 'special case'. Any attempt to model the broad features of spiritual care in terms of spiritual intuitions must take into account and include the religiocultural context in which such selection takes place.

Consequently, modifying the model I originally proposed in the light of further consideration of the population-level processes of selection, it is possible to make the following tentative predictions regarding the key elements of a model of spiritual care that is informed by the evidence and by the perspective of evolutionary psychology generally:

1. There will be some forms of 'religious coping' which can be explained in terms of CSR and selective pressures giving rise to individual spiritual intuitions (Kevern 2012a). These can provide some explanation of recurring elements in spiritual care such as the search for agency.

2. However, within-population selection predicts for variation in the strength, salience and character of these cognitively-driven intuitions 
(Johnson 2012). Consequently, blanket-level injunctions and protocols for particular spiritual care interventions will never be reliable.

3. Furthermore, population-level selection will be influenced by the need to adapt to cultural, environmental and technological conditions (Norenzayan 2013) which entails the need to take account of particular religious and social backgrounds when offering spiritual care to individuals: the socioreligious context cannot be 'bracketed out' of spiritual care.

4. Nevertheless, inter-population selection promotes 'prosocial' values and practices (such as mutuality and reinforcing rites) which favour the survival of the group as a whole, even potentially at cost to the personal survival of the individual (Baumard \& Chevallier 2015; Morewedge \& Clear 2008; Norenzayan et al. 2012). Consequently, there are some shared values held by most if not all persistent religious organisations which reinforce the belonging and security of the individual and therefore need to be taken into account in personcentred care generally.

\section{Conclusions}


The title of the paper which began this exchange of views posed a question, "Can Cognitive Science rescue 'spiritual care' from a metaphysical backwater?". The answer appears to be that it cannot, or at least not comprehensively and consistently. Paley and I clearly agree on this point, although for instructively divergent reasons.

From his paper, I infer that Paley's main reason for rejecting the proposal is that he has a more persuasive counter-narrative in which he understands the use of the term spirituality in health care as 'ideologically driven' (p.9). This is apparent from the inclusion of his counter-narrative as part of his response to my paper, a strategy which, paradoxically, seems 'ideologically driven' in its own right. His secondary argument is that my proposal was based upon "four logical non-sequiturs and an 'undefended assumption'" and had therefore proved itself hollow. In the analysis above I have responded to these five points and used them as the basis for a more sophisticated reflection.

My own reasons for responding to the question ("Can the cognitive science of religion from a metaphysical backwater?") in the negative are rather different, and boil down to three points. First, there is a material point: it has become apparent in the course of the discussion that the field of view of CSR is in itself too narrow to encompass the range of selection pressures and consequent physical, psychological and cultural artefacts which converge to contribute to an individual's spiritual or religious world. Secondly, there is an associated methodological one: that patients in acute hospital wards cannot 
be treated as inhabiting a religiously-isolated world, driven back on 'quick and dirty' religious thinking, even for the purposes of a thought experiment. Finally, a discursive point: that 'spiritual care' does not need to be rescued from a metaphysical backwater because it does not need to have a metaphysics. The philosophy of patient-centred care is, by conviction as well as by accident, resistant to being captured by a single metaphysical description of the human condition: it does not seek to prescribe or describe in advance the basic elements and norms of human existence or human preference, but seeks to enable the individual patient to identify their own needs, then to meet them.

Nevertheless, in the course of the discussion it has been possible to sketch out what a model of spiritual care informed by evolutionary psychology in a broader framework might look like, and what it implies for the provision of spiritual care. In short, it predicts that there will be some elements of individual spiritual coping (and so of spiritual care) which can be explained by a consideration of CSR at the individual level; and that there will be other elements (such as the broadly shared values of mutuality and trustworthiness) which will be reinforced by religious organization and belonging at the communal level and explicable by evolutionary anthropology. It therefore makes possible testable predictions about how 'spiritual care' might most effectively be offered, the detailed development of which must await a later paper. 
Practically, the model also points to three conclusions in relation to the provision of spiritual care. First, a general point: given the supposed common origins of spiritual need in the evolution of individual cognition on the one hand and the fundamental selection pressures governing groups on the other, there is some theoretical justification for seeking common themes in 'spiritual care' which enhance patient wellbeing and coping. Secondly, however, given the predicted variation between individuals, the character of spiritual care must be understood as dialogic rather than didactic, therapeutic rather than interventionist. Finally, the relation of organized religious networks and their officials to this process is complex. On the one hand, they are likely to be the source of religious practices which support the patient's wellbeing and coping; on the other, since the primary selection pressures operative on them concern the survival of the group rather than the individual, they may be a source of tensions within the individual or between the individual and their social group. Consequently, it does not necessarily follow that spiritual care is best given by a representative of the patient's religious group (Kevern 2012b)

\section{References}

Atran, S., 2004. In gods we trust: The evolutionary landscape of religion, 
Oxford University Press.

Balboni, M.J. et al., 2014. Nurse and physician barriers to spiritual care provision at the end of life. Journal of pain and symptom management, 48(3), pp.400-410.

Barrett, J.L., 2011. Cognitive science, religion, and theology: From human minds to divine minds, Templeton Press.

Baumard, N. \& Chevallier, C., 2015. The nature and dynamics of world religions: a life-history approach. Proceedings of the Royal Society B: Biological Sciences, 282(1818), p.20151593. Available at: http://rspb.royalsocietypublishing.org/lookup/doi/10.1098/rspb.2015.159 3.

Bloom, P., 2009. Religious belief as an evolutionary accident. The believing primate: Scientific, philosophical, and theological reflections on the origin of religion, pp.118-127.

Buss, D.M. et al., 1998. Adaptations, exaptations, and spandrels. American psychologist, 53(5), p.533.

Clarke, J., 2013. Spiritual Care in Everyday Nursing Practice: A New Approach, Palgrave Macmillan.

Cockell, N. \& McSherry, W., 2012. Spiritual care in nursing: an overview of published international research. Journal of Nursing Management, 20(8), pp.958-969.

Department of Health, 2010. Spiritual care at the end of life. A systematic review of the literature, London. Available at: https://www.gov.uk/government/uploads/system/uploads/attachment_da 
ta/file/215798/dh_123804.pdf.

Evans-Pritchard, E.E. \& Evans-Pritchard, E.E., 1965. Theories of primitive religion, Clarendon Press Oxford.

Fichte, J.G., 1982. Foundations of the Entire Science of Knowledge (1794-

95), The Science of Knowledge, with the First and Second Introductions, ed. and trans. Peter Heath and John Lachs (Cambridge: Cambridge University Press).

Gall, T.L., Malette, J. \& Guirguis-Younger, M., 2011. Spirituality and Religiousness: A Diversity of Definitions. Journal of Spirituality in Mental Health, 13(3), pp.158-181.

Gould, S.J., 1991. Exaptation: A crucial tool for an evolutionary psychology. Journal of social issues, $47(3), \mathrm{pp} .43-65$.

Grandy, R.E., 1992. Semantic fields, prototypes, and the lexicon. Frames, fields, and contrasts: New essays in semantic and lexical organization, pp.103-122.

Heelas, P. et al., 2005. The Spiritual Revolution: Why Religion is Giving Way to Spirituality., Blackwell.

Johnson, D., 2012. What are atheists for? Hypotheses on the functions of non-belief in the evolution of religion. Religion, Brain \& Behavior, 2(1), pp.48-70.

Kevern, P., 2013a. Can Cognitive Science Rescue "Spiritual Care" from a Metaphysical Backwater? Journal for the Study of Spirituality, 3(1), pp.817. Available at:

http://www.maneyonline.com/doi/10.1179/2044024313Z.0000000001. 
Kevern, P., 2013b. Can Reductionists Be Chaplains Too? Reflections on the Vacuousness of "Spirituality." Health and Social Care Chaplaincy, 13(2), pp.2-8. Available at:

http://www.equinoxpub.com/journals/index.php/HSCC/article/view/1679 8.

Kevern, P., 2012a. In search of a theoretical basis for understanding religious coping: Initial testing of an explanatory model. Mental Health, Religion \& Culture, 15(1), pp.23-37.

Kevern, P., 2012b. Who can give "spiritual care"? The management of spiritually sensitive interactions between nurses and patients. Journal of Nursing Management, 20(8), pp.981-989.

Kevern, P. \& Hill, L., 2015. "Chaplains for well-being"in primary care: analysis of the results of a retrospective study. Primary health care research \& development, 16(01), pp.87-99.

Koenig, H., King, D. \& Carson, V.B., 2012. Handbook of religion and health, Oxford university press.

Lewinson, L.P., McSherry, W. \& Kevern, P., 2015. Spirituality in preregistration nurse education and practice: A review of the literature. Nurse Education Today, pp.1-9. Available at: http://linkinghub.elsevier.com/retrieve/pii/S0260691715000428.

Lorenz, K.Z., 1966. Evolution of ritualization in the biological and cultural spheres. Philosophical Transactions of the Royal Society of London. Series B, Biological Sciences, 251(772), pp.273-284.

McSherry, W. \& Jamieson, S., 2011. An online survey of nurses' perceptions 
of spirituality and spiritual care. Journal of clinical nursing, 20(11-12), pp.1757-67. Available at:

http://www.ncbi.nlm.nih.gov/pubmed/21385257 [Accessed October 29, 2014].

McSherry, W. \& Ross, L., 2015. A spiritual shortfall? Nursing Standard, 29(35), pp.22-23. Available at:

http://dx.doi.org/10.7748/ns.29.35.22.s24.

Morewedge, C.K. \& Clear, M.E., 2008. Anthropomorphic God concepts engender moral judgment. Social Cognition, 26(2), p.182.

Mowat, H., Bunniss, S. \& Kelly, E., 2012. Community Chaplaincy Listening: working with General Practitioners to support patient wellbeing. Scottish Journal of Healthcare Chaplaincy, 15(1), pp.21-26.

Murray, M. \& Goldberg, A., 2005. Evolutionary accounts of religion: Explaining and explaining away.

Nascimento, L.C. et al., 2016. Spiritual Care: The Nurses' Experiences in the Pediatric Intensive Care Unit. Religions, 7(3), p.27.

Nolan, S., 2011. Hope beyond (redundant) hope: how chaplains work with dying patients. Palliative medicine, 25(1), pp.21-5. Available at: http://www.ncbi.nlm.nih.gov/pubmed/21245080 [Accessed November $14,2014]$.

Nolan, S., 2009. In defence of the indefensible: an alternative to John Paley's reductionist, atheistic, psychological alternative to spirituality. Nursing Philosophy, 10(3), pp.203-213.

Norenzayan, A., 2013. Big gods: How religion transformed cooperation and 
conflict, Princeton University Press.

Norenzayan, A. et al., 2014. The cultural evolution of prosocial religions. Brain and Behavioral Sciences, (1).

Norenzayan, A., Henrich, J. \& Slingerland, E., 2012. Religious prosociality: A synthesis. Psych.Ubc.Ca, pp.1-21. Available at:

http://www2.psych.ubc.ca/ henrich/pdfs/Norenzayanetal_final.pdf.

Paley, J., 2009. Keep the NHS secular. Nursing Standard, 23(43), pp.26-27. Available at:

http://ezproxy.staffs.ac.uk/login?url=http://search.proquest.com/docview /219864308?accountid=17254.

Paley, J., 2008a. Spirituality and nursing: a reductionist approach. Nursing Philosophy, 9(1), pp.3-18.

Paley, J., 2010. Spirituality and reductionism: Three replies. Nursing Philosophy, 11(3), pp.178-190.

Paley, J., 2008b. Spirituality and secularization: Nursing and the sociology of religion. Journal of Clinical Nursing, 17(2), pp.175-186.

Paley, J., 2008c. The concept of spirituality in palliative care: an alternative view. International journal of palliative nursing, 14(9), pp.448-452.

Paley, J., 2015. Why the cognitive science of religion cannot rescue "spiritual care." Nursing Philosophy, 16(4), pp.213-225.

Pargament, K.I. et al., 2010. Religion and the Problem-Solving Process: Three Styles of Coping. , 27(1), pp.90-104.

Pattison, S., 2001. Dumbing down the spirit. Spirituality in health care contexts, pp.33-47. 
Peoples, H.C. \& Marlowe, F.W., 2012. Subsistence and the Evolution of Religion. Human Nature, 23(3), pp.253-269.

Pesut, B., 2008. A reply to "Spirituality and nursing: a reductionist approach" by John Paley. Nursing philosophy: an international journal for healthcare professionals, 9(2), pp.131-137; discussion 138-140.

Powell, R. \& Clarke, S., 2012. Religion as an evolutionary byproduct: A critique of the standard model. British Journal for the Philosophy of Science, 63(3), pp.457-486.

Puchalski, C.M. et al., 2014. Spirituality and Health: The Development of a Field. Academic Medicine, 89(1). Available at: http://journals.Iww.com/academicmedicine/Fulltext/2014/01000/Spirituali ty_and_Health__The_Development_of_a.9.aspx.

Pyysiäinen, I. \& Hauser, M., 2010. The origins of religion : evolved adaptation or by-product? Trends in Cognitive Sciences, 14(3), pp.104-109. Available at: http://www.sciencedirect.com/science/article/pii/S1364661309002897. Reinert, K.G. \& Koenig, H.G., 2013. Re-examining definitions of spirituality in nursing research. Journal of Advanced Nursing, 69(12), pp.2622-2634. Rushton, L., 2014. What are the barriers to spiritual care in a hospital setting? British Journal of Nursing, 23(7).

Sosis, R., 2009. The Adaptationist-Byproduct Debate on the Evolution of Religion: Five Misunderstandings of the Adaptationist Program. Journal of Cognition and Culture, 9, pp.315-332.

Swinton, J., 2011. Being in the Moment: Developing a Contemplative 
Approach to Spiritual Care with People who have Dementia. In A. Jewell, ed. Spirituality and Personhood in Dementia. London: Jessica Kingsley Publishers, pp. 175-185.

Swinton, J., 2014. Spirituality-in-Healthcare: Just Because it May Be "Made Up"Does Not Mean That it is Not Real and Does Not Matter (Keynote 5). Journal for the Study of Spirituality, 4(2), pp.162-173.

Swinton, J. \& Pattison, S., 2010. Moving beyond clarity: towards a thin, vague, and useful understanding of spirituality in nursing care. Nursing Philosophy, 11(4), pp.226-237.

Tanyi, R.A., 2002. Towards clarification of the meaning of spirituality. Journal of advanced nursing, 39(5), pp.500-509.

Weathers, E., McCarthy, G. \& Coffey, A., 2015. Concept Analysis of Spirituality: An Evolutionary Approach. In Nursing forum. Wiley Online Library.

Wilson, D.S., 2010. Darwin's cathedral: Evolution, religion, and the nature of society, University of Chicago Press.

World Health Organization, 1998. WHOQOL and spirituality, religiousness and personal beliefs (SRPB), Geneva: World Health Organization. Available at: http://apps.who.int/iris/bitstream/10665/70897/1/WHO_MSA_MHP_98.2_ eng.pdf?ua $=1$.

Zinnbauer, B.J. et al., 1997. Religion and Spirituality: Unfuzzying the Fuzzy. Journal for the Scientific Study of Religion, 36(4), pp.549-564. Available at: http://www.jstor.org/stable/1387689. 